\title{
Performance of Current Intensive Care Unit Ventilators During Pressure and Volume Ventilation
}

\author{
Andrew D Marchese, Demet Sulemanji MD, Daniel Chipman RRT, Jesús Villar PhD MD, \\ and Robert M Kacmarek PhD RRT FAARC
}

\begin{abstract}
BACKGROUND: Intensive-care mechanical ventilators regularly enter the market, but the gasdelivery capabilities of many have never been assessed. METHODS: We evaluated 6 intensive-care ventilators in the pressure support (PS), pressure assist/control (PA/C), and volume assist/control (VA/C) modes, with lung-model mechanics combinations of compliance and resistance of $60 \mathrm{~mL} / \mathrm{cm}$ $\mathrm{H}_{2} \mathrm{O}$ and $10 \mathrm{~cm} \mathrm{H}_{2} \mathrm{O} / \mathrm{L} / \mathrm{s}, 60 \mathrm{~mL} / \mathrm{cm} \mathrm{H}_{2} \mathrm{O}$ and $5 \mathrm{~cm} \mathrm{H} \mathrm{H}_{2} \mathrm{O} / \mathrm{L} / \mathrm{s}$, and $30 \mathrm{~mL} / \mathrm{cm} \mathrm{H}_{2} \mathrm{O}$ and $10 \mathrm{~cm} \mathrm{H}_{2} \mathrm{O} / \mathrm{L} / \mathrm{s}$, and inspiratory muscle effort of 5 and $10 \mathrm{~cm} \mathrm{H}_{2} \mathrm{O}$. PS and PA/C were set to $15 \mathrm{~cm} \mathrm{H}_{2} \mathrm{O}$, and PEEP to 5 and $15 \mathrm{~cm} \mathrm{H}_{2} \mathrm{O}$ in all modes. During $\mathrm{VA} / \mathrm{C}$, tidal volume was set at $500 \mathrm{~mL}$ and inspiratory time was set at 0.8 second. Rise time and termination criteria were set at the manufacturers' defaults, and to an optimal level during PS and PA/C. RESULTS: There were marked differences in ventilator performance in all 3 modes. VA/C had the greatest difficulty meeting lung model demand and the greatest variability across all tested scenarios and ventilators. From high to low inspiratory muscle effort, pressure-to-trigger, time for pressure to return to baseline, and triggering pressuretime product decreased in all modes. With increasing resistance and decreasing compliance, tidal volume, pressure-to-trigger, time-to-trigger, time for pressure to return to baseline, time to $90 \%$ of peak pressure, and pressure-time product decreased. There were large differences between the default and optimal settings for all the variables in PS and PA/C. Performance was not affected by PEEP. CONCLUSIONS: Most of the tested ventilators performed at an acceptable level during the majority of evaluations, but some ventilators performed inadequately during specific settings. Bedside clinical evaluation is needed. Key words: ventilator; mechanical ventilation; intensive care; pressure support; pressure assist/control; volume assist/control. [Respir Care 2011;56(7):928-940. (c) 2011 Daedalus Enterprises]
\end{abstract}

\begin{abstract}
Mr Marchese, Mr Chipman RRT, and Dr Kacmarek are affiliated with the Department of Respiratory Care, Massachusetts General Hospital, Boston, Massachusetts. Dr Sulemanji is affiliated with the Departments of Respiratory Care and Anesthesiology and Critical Care, Harvard Medical School and Massachusetts General Hospital, Boston, Massachusetts. Dr Villar is affiliated with the Centro de Investigación Biomédica en Red (CIBER) de Enfermedades Respiratorias, Instituto de Salud Carlos III, Madrid, Spain, and with the Multidisciplinary Organ Dysfunction Evaluation Research Network, Research Unit, Hospital Universitario Dr Negrin, Las Palmas de Gran Canaria, Spain.
\end{abstract}

Mr Marchese presented a version of this report at the OPEN FORUM at the 54th International Respiratory Congress of the American Association for Respiratory Care, held December 13-16, 2008, in Anaheim, California.

Deputy Editor Richard Branson guided this paper through peer review.

\section{Introduction}

Manufacturers continue to modify, upgrade, and introduce new intensive care unit (ICU) ventilators. Their intent is to design ventilators that better manage patients' ventilatory and oxygenation failure and to provide adjuncts and new modes of ventilation to make ventilation safer, to improve patient-ventilator synchrony, to facilitate better

See the Related Editorial on Page 1052 gas exchange, and to wean patients faster. ${ }^{1}$ Over the years, several groups have evaluated the performance of ICU 
ventilators, ${ }^{2-12}$ which has helped clinicians differentiate those ventilators' operational variability.

Today there are 6 mechanical ventilators available in the United States that are considered top-of-the-line ICU ventilators: Puritan Bennett 840 (PB840, Covidien, Bolder, Colorado); Servo-i (Maquet Medical, Danvers, Massachusetts); e500 (Newport, Costa Mesa, California); Carestation (General Electric, Madison, Wisconsin); G5 (Hamilton Medical, Reno, Nevada), and Evita XL (Dräger, Telford, Pennsylvania). Only the PB840, Servo-i, Carestation, and Evita XL have been evaluated during adult ventilation, but only in the pressure support (PS) mode. ${ }^{9,12}$ These ventilators have been tested for their ability to ventilate neonatal and pediatric patients ${ }^{11}$ and to ventilate noninvasively, ${ }^{8,10}$ but none of them have been evaluated during invasive adult pressure assist/control (PA/C) or volume assist/control $(\mathrm{VA} / \mathrm{C})$ ventilation. We compared the gas-delivery capabilities of the PB840, Servo-i, e500, Carestation, G5, and Evita XL during assisted ventilation in the PS, PA/C and VA/C modes. We hypothesized that, although we expected to find performance differences, we expected all the ventilators to perform in a clinically acceptable manner in most of the test scenarios.

\section{Methods}

\section{Lung Model}

We tested the ventilators with a servo-controlled lung model (ASL 5000, IngMar Medical, Pittsburg, Pennsylvania) that allows precise simulation of varying lung mechanics, inspiratory patterns, and lung compliance and resistance. ${ }^{10}$ The characteristics of the simulated patient effort are determined by setting the spontaneous breathing rate, maximum negative inspiratory muscle pressure $\left(\mathrm{P}_{\text {mus }}\right)$, inspiratory time, inspiratory hold time, and the time for return of pressure to baseline. ${ }^{11}$

\section{Lung Model Settings}

We tested 3 combinations of lung mechanics: compliance $60 \mathrm{~mL} / \mathrm{cm} \mathrm{H}_{2} \mathrm{O}$ with resistance $10 \mathrm{~cm} \mathrm{H}_{2} \mathrm{O} / \mathrm{L} / \mathrm{s}(\mathrm{C} 60$ / $\mathrm{R} 10$ ); compliance $60 \mathrm{~mL} / \mathrm{cm} \mathrm{H}_{2} \mathrm{O}$ with resistance $5 \mathrm{~cm} \mathrm{H}_{2} \mathrm{O} /$

\footnotetext{
This research was partly supported by Covidien, Dräger Medical, General Electric, Hamilton Medical, and Newport Medical. Mr Chipman has disclosed a relationship with Maquet Medical. Dr Villar has disclosed a relationship with Maquet Medical. Dr Kacmarek has disclosed relationships with Covidien, Carefusion, Dräger Medical, General Electric, Hamilton Medical, Newport Medical, and KCI. The other authors have disclosed no conflicts of interest.
}

Correspondence: Robert M Kacmarek, Respiratory Care Department, Massachusetts General Hospital, 55 Fruit Street, Ellison 401, Boston MA 02114. E-mail: rkacmarek@partners.org.

DOI: $10.4187 /$ respcare.00981
$\mathrm{L} / \mathrm{s}$ (C60/R5); and compliance $30 \mathrm{~mL} / \mathrm{cm} \mathrm{H}_{2} \mathrm{O}$ with resistance $10 \mathrm{~cm} \mathrm{H}_{2} \mathrm{O} / \mathrm{L} / \mathrm{s}(\mathrm{C} 30 / \mathrm{R} 10)$. We set the respiratory rate at 20 breaths $/ \mathrm{min}$, inspiratory time at 0.8 second, and total breath-cycle time at 3 seconds. The inspiratory time was achieved with an active inspiration of $3.5 \%$ of breath-cycle time $(3 \times 0.035$, or $0.105 \mathrm{~s})$, a hold at maximum muscle effort $\left(\mathrm{P}_{\text {mus }}\right)$ of $0.5 \%$ of breath-cycle time $(0.015 \mathrm{~s})$, and a return-of-pressure-to-baseline of $22.7 \%$ of breath-cycle time $(0.68 \mathrm{~s})$. Thus:

$$
0.105+0.015+0.68=0.8 \text { s inspiratory time }
$$

We tested maximum $\mathrm{P}_{\text {mus }}$ of 5 and $10 \mathrm{~cm} \mathrm{H}_{2} \mathrm{O}$. Table 1 shows the tidal volumes $\left(\mathrm{V}_{\mathrm{T}}\right)$ and peak flows.

\section{Ventilator Settings}

Before all the tests we set the flow trigger sensitivity as sensitive as possible without auto-triggering, by setting the sensitivity to cause auto-triggering and then reducing the sensitivity until auto-triggering stopped (Table 2 ). We tested PEEP of 5 and $15 \mathrm{~cm} \mathrm{H}_{2} \mathrm{O}$ in each mode.

Pressure Support. We set the driving pressure at $15 \mathrm{~cm} \mathrm{H}_{2} \mathrm{O}$. The rise time and termination criteria were set at both the manufacturers' defaults and at the optimal level. We deemed the optimal rise time setting to be as short as possible while maintaining an initial airway pressure spike beneath peak airway pressure and ensuring no severe ringing in the airway pressure waveform (see Table 2). ${ }^{10,11}$ Furthermore, we adjusted rise time to avoid inconsistencies and inaccuracies in the time-to-90\%-of-peak-pressure (T90) measurements (see Evaluated Variables section below). If pressurization was too rapid, this timing variable periodically shifted from representing the aggressive initial airway pressure spike to representing the more gradual rise of airway pressure to target. To avoid a large variance in T90, we set the optimal rise time to ensure that T90 occurred after the initial airway pressure spike. Optimal termination criteria were set to ensure that the lung model and ventilator terminated the breath simultaneously ( $\pm 5 \%)$ (see Table 2). ${ }^{10,11}$

In the Evita XL the breath-termination criterion is internally fixed at $25 \%$ of peak flow. We set the e500 to automatically regulate the termination criteria and rise time in the optimal test conditions. The e500 was unable to ventilate the lung model in the C60/R5 scenario because of incompatibilities in repositioning frequencies between the ventilator and the lung model, resulting in oscillations, so with the e500 we omitted the C60/R5 tests from the analysis.

Pressure Assist/Control. Pressure above PEEP was set at $15 \mathrm{~cm} \mathrm{H}_{2} \mathrm{O}$ with inspiratory time 0.8 second. As in the PS tests, we conducted the PA/C tests with both the manufacturers' defaults and the optimal rise times (see Table 2). 
Table 1. Lung Model Settings and Resultant Spontaneous Unassisted Peak Flows and Tidal Volumes

\begin{tabular}{lcccc}
\hline $\begin{array}{c}\text { Compliance } \\
\left(\mathrm{mL} / \mathrm{cm} \mathrm{H}_{2} \mathrm{O}\right)\end{array}$ & $\begin{array}{c}\text { Resistance } \\
\left(\mathrm{cm} \mathrm{H}_{2} \mathrm{O} / \mathrm{L} / \mathrm{min}\right)\end{array}$ & $\begin{array}{c}\text { Muscle } \\
\text { Effort } \\
\left(\mathrm{cm} \mathrm{H}_{2} \mathrm{O}\right)\end{array}$ & $\begin{array}{c}\text { Peak } \\
\text { Flow } \\
(\mathrm{L} / \mathrm{min})\end{array}$ & $\begin{array}{c}\text { Tidal } \\
\text { Volume } \\
(\mathrm{mL})\end{array}$ \\
\hline 60 & 10 & 5 & 25.1 & 149 \\
60 & 5 & 5 & 41.7 & 224 \\
30 & 10 & 5 & 21.6 & 111 \\
60 & 10 & 10 & 49.8 & 297 \\
60 & 5 & 10 & 83.2 & 446 \\
30 & 10 & 10 & 43.0 & 221 \\
\hline
\end{tabular}

Volume Assist/Control. We set the maximum flow or inspiratory-expiratory ratio to ensure an inspiratory time of 0.8 second ( $\pm 5 \%$ ) with a set $\mathrm{V}_{\mathrm{T}}$ of $500 \mathrm{~mL}$. When possible, we assessed each ventilator with both a square waveform and a decelerating-flow waveform. However, the Carestation, Evita XL, and Servo-i only deliver a square waveform. We conducted $24 \mathrm{PS}$ and PA/C tests with all the ventilators, $24 \mathrm{VA} / \mathrm{C}$ tests with the PB840, e500, and G5, and $12 \mathrm{VA} / \mathrm{C}$ tests with the Servo-i, Carestation, and Evita XL, because they only provide a square waveform.

\section{Evaluated Variables}

We evaluated ventilator triggering and initial gas delivery with the following variables (Fig. 1). ${ }^{10,11}$

- Time to trigger: the time (in milliseconds) from the start of the breath to the maximum negative deflection in airway pressure

- Pressure to trigger: the pressure difference (in $\mathrm{cm}_{2} \mathrm{O}$ ) between the initial airway pressure at the start of the breath and the maximum negative deflection in airway pressure

- Time to baseline: the time (in milliseconds) from ventilator triggering to the point when the airway pressure reached the baseline pressure (PEEP)

- Time to $90 \%$ of peak pressure (T90): the time (in milliseconds) from ventilator triggering to the point when airway pressure reached $90 \%$ of its peak value. Since volume ventilation has a fixed flow pattern, we did not measure T90 during volume ventilation.

- Pressure-time product (PTP): the area bounded by baseline pressure and the airway pressure waveform from the start of the breath to the point when baseline is reestablished

- $\mathrm{V}_{\mathrm{T}}$ : the difference in lung volume between the beginning and end of exhalation

\section{Data Collection and Analysis}

With the lung model's software (Labview, National Instruments, Austin, Texas) we captured (at $512 \mathrm{~Hz}$ ) approximately 20 breaths in each test scenario. We used a $40-\mathrm{mL}$ breath-detection threshold to capture each waveform. For each simulation we analyzed 5 representative breaths, after visual inspection in the software's post-run analysis window. In most cases we computed the performance variables with the Labview software. However, since most of the variables were referenced to a predictable airway pressure pattern, many $\mathrm{VA} / \mathrm{C}$ scenarios required manual calculations. We recomputed time-to-trigger, pressure-to-

Table 2. Average Settings for Trigger Sensitivity, Rise Time, and Termination Criteria

\begin{tabular}{|c|c|c|c|c|c|c|c|c|c|c|c|c|c|c|c|c|c|c|}
\hline & \multicolumn{3}{|c|}{840} & \multicolumn{3}{|c|}{ Servo-i } & \multicolumn{3}{|c|}{ e500 } & \multicolumn{3}{|c|}{ Carestation } & \multicolumn{3}{|c|}{ G5 } & \multicolumn{3}{|c|}{ Evita XL } \\
\hline & PS & $\mathrm{PA} / \mathrm{C}$ & $\mathrm{VA} / \mathrm{C}$ & PS & $\mathrm{PA} / \mathrm{C}$ & $\mathrm{VA} / \mathrm{C}$ & PS & $\mathrm{PA} / \mathrm{C}$ & $\mathrm{VA} / \mathrm{C}$ & PS & $\mathrm{PA} / \mathrm{C}$ & $\mathrm{VA} / \mathrm{C}$ & PS & $\mathrm{PA} / \mathrm{C}$ & $\mathrm{VA} / \mathrm{C}$ & PS & $\mathrm{PA} / \mathrm{C}$ & $\mathrm{VA} / \mathrm{C}$ \\
\hline \multicolumn{19}{|l|}{ Default/square } \\
\hline Trigger sensitivity & 0.47 & 0.43 & 0.69 & 9.8 & 10.0 & 7.2 & 0.71 & 0.60 & 0.61 & 1 & 1 & 1 & 0.58 & 0.54 & 0.63 & 0.3 & 0.3 & 0.3 \\
\hline Rise time $(\%)$ & 50 & 50 & NA & 0.15 & 0.15 & NA & 10 & 10 & NA & 50 & 50 & NA & 50 & 50 & NA & 0.2 & 0.2 & NA \\
\hline $\begin{array}{l}\text { Termination criteria } \\
(\%)\end{array}$ & 10 & NA & NA & 30 & NA & NA & 25 & NA & NA & 25 & NA & NA & 25 & NA & NA & $25^{*}$ & NA & NA \\
\hline \multicolumn{19}{|l|}{ Optimal/decelerating } \\
\hline Trigger sensitivity & 0.57 & 0.48 & 0.63 & 9.8 & 9.8 & 9.8 & 0.60 & 0.60 & 0.60 & 1 & 1 & 1 & 0.67 & 0.58 & 0.58 & 0.3 & 0.3 & 0.3 \\
\hline Rise time $(\%)$ & 87 & 82 & NA & 0.01 & 0.02 & NA & Auto $\dagger$ & Auto $\dagger$ & NA & 50 & 50 & NA & 50 & 50 & NA & 0.06 & 0.04 & NA \\
\hline $\begin{array}{l}\text { Termination criteria } \\
\quad(\%)\end{array}$ & 13 & NA & NA & 20 & NA & NA & Auto $\dagger$ & NA & NA & 23 & NA & NA & 47 & NA & NA & $25^{*}$ & NA & NA \\
\hline $\begin{array}{l}\text { * Factory set: no adjustment po } \\
\dagger \text { Auto = ventilator automatical } \\
\mathrm{NA}=\text { not applicable for this m } \\
\mathrm{PS}=\text { pressure support. } \\
\mathrm{PA} / \mathrm{C}=\text { pressure assist } / \text { control. } \\
\mathrm{VA} / \mathrm{C}=\text { volume assist } / \text { control }\end{array}$ & $\begin{array}{l}\text { ible. } \\
\text { adjusts } \\
\text { de or ve }\end{array}$ & $\begin{array}{l}\text { no displa } \\
\text { tilator }\end{array}$ & & & & & & & & & & & & & & & & \\
\hline
\end{tabular}




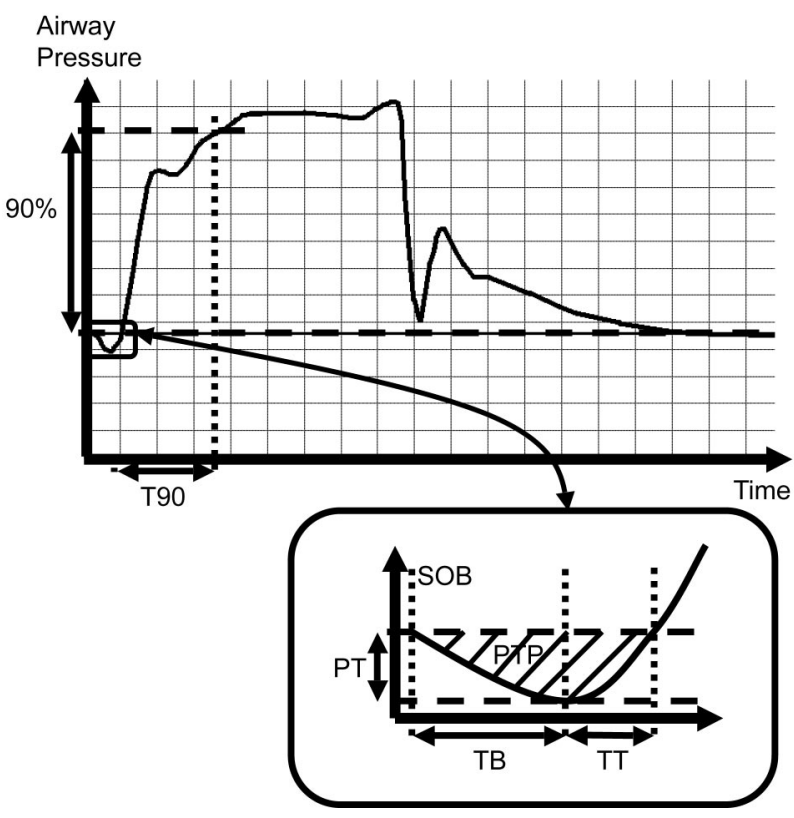

Fig. 1. Tidal volume, time to trigger (TT), pressure to trigger (PT), time to $90 \%$ of peak pressure, time to return to baseline (TB), and pressure-time product (PTP). SOB = start of breath.

trigger, time-to-baseline-pressure, and PTP in 11 to 14 of the $24 \mathrm{VA} / \mathrm{C}$ scenarios for each ventilator. In those scenarios there were multiple instances of airway pressure rising above and then falling beneath the baseline pressure, which caused the lung model's software to incorrectly reference ventilator triggering and flow delivery. Fig. 2 shows examples of airway pressure and flow waveforms. We manually calculated the performance variables from raw waveform data (*.dtb files) generated by the Labview software. Statistical analysis was performed with statistics software (SPSS 15.0, SPSS, Chicago, Illinois).

We used independent-samples $t$ tests to determine the performance differences between the different $\mathrm{P}_{\text {mus }}$, PEEP, and optimal and default ventilator settings within each ventilator. We used analysis of variance and the Bonferroni test for multiple comparisons to determine the differences between the various lung-mechanics combinations and the differences in overall performance between the ventilators. The performance differences we considered "important" are only those that were both statistically significant $(P<.05)$ and at least $10 \%$ different in mean value.

\section{Results}

\section{Ventilator Differences}

There were important differences in all the ventilator performance characteristics among the tested ventilators in the PS, PA/C, and VA/C modes (Table 3).
Servo-i - Worst Case

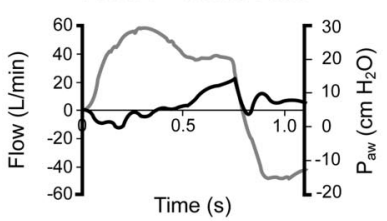

PB 840 - Worst Case

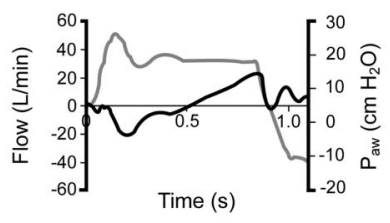

Newport - Worst Case

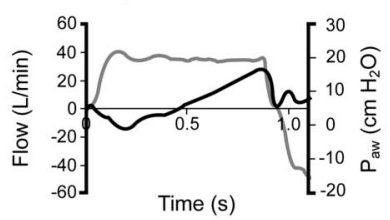

G5 - Worst Case
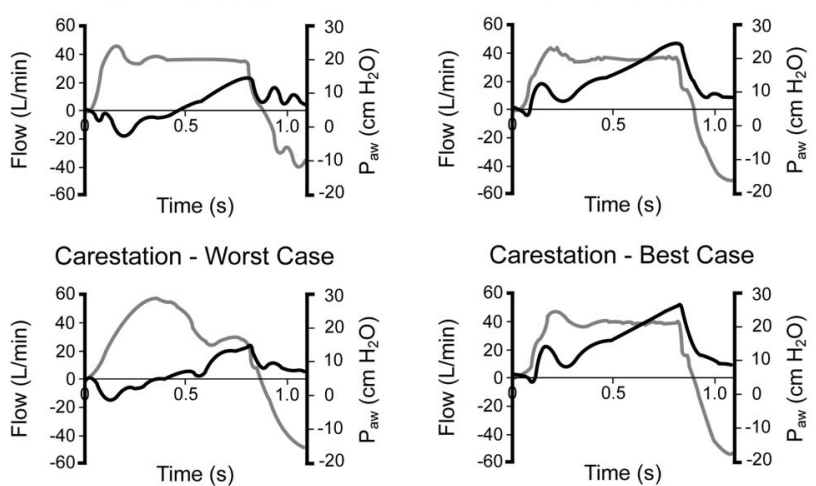

Exita XL - Worst Case
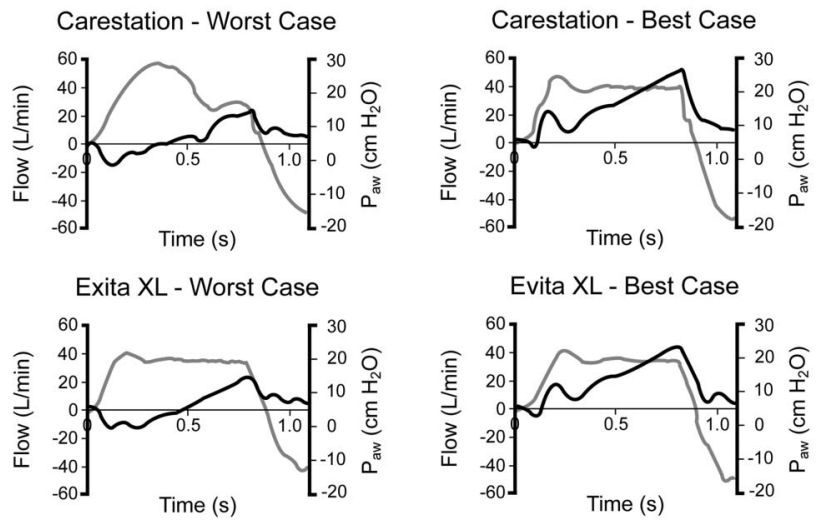

Evita XL - Best Case

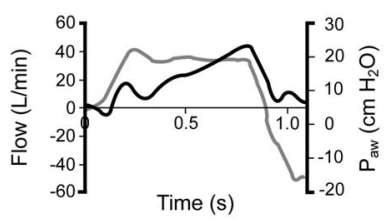

Fig. 2. Example flow waveforms (grey) and airway pressure $\left(P_{\text {aw }}\right)$ waveforms (black) from the 6 tested ventilators. The "worst case" and "best case" were the scenarios in which performance was poorest and best, respectively. In the worst-case scenarios note the lengthy period that airway pressure remained below baseline and the difficulty in determining time to baseline because of the increase (sometimes crossing baseline) then decrease in airway pressure after triggering.

\section{Effects of Ventilator Settings}

In PS, the change from default to optimal ventilator settings resulted in several important differences (Fig. 3). $V_{T}$ remained unchanged with all the ventilators except the $\mathrm{G} 5$, with which $\mathrm{V}_{\mathrm{T}}$ decreased with the optimal configuration. Time-to-trigger decreased with the optimal configuration with the PB840, Servo-i, and Evita XL. Similarly, 
Table 3. Lung Model Test Results

\begin{tabular}{|c|c|c|c|c|c|c|c|}
\hline Mode & Ventilator & $\begin{array}{c}\text { Tidal } \\
\text { Volume }(\mathrm{mL})\end{array}$ & $\begin{array}{c}\text { Trigger } \\
\text { Time (ms) }\end{array}$ & $\begin{array}{l}\text { Pressure } \\
\text { to Trigger } \\
\left(\mathrm{cm} \mathrm{H}_{2} \mathrm{O}\right)\end{array}$ & $\begin{array}{c}\text { Time to } 90 \% \text { of } \\
\text { Peak Pressure }(\mathrm{ms})\end{array}$ & $\begin{array}{c}\text { Time to } \\
\text { Return to } \\
\text { Baseline (ms) }\end{array}$ & $\begin{array}{c}\text { Pressure-Time } \\
\text { Product } \\
\left(\mathrm{cm} \mathrm{H} \mathrm{H}_{2} \mathrm{O} \cdot \mathrm{s} / \mathrm{min}\right) \\
\end{array}$ \\
\hline \multirow[t]{6}{*}{ Pressure Support } & 840 & $795 \pm 229^{*}$ & $81 \pm 16^{*}$ & $1.9 \pm 1.0^{*}$ & $210 \pm 52 \dagger$ & $29 \pm 7 \ddagger$ & $102 \pm 64 *$ \\
\hline & Servo-i & $775 \pm 208^{*}$ & $78 \pm 11$ & $2.2 \pm 0.9^{*}$ & $207 \pm 43 \dagger$ & $20 \pm 6$ & $90 \pm 47 *$ \\
\hline & e500 & $600 \pm 146$ & $72 \pm 7$ & $1.6 \pm 0.4$ & $196 \pm 41 \dagger$ & $25 \pm 10 \ddagger$ & $63 \pm 24$ \\
\hline & Carestation & $763 \pm 211^{*}$ & $84 \pm 6^{*}$ & $2.8 \pm 1.0^{*}$ & $185 \pm 21$ & $32 \pm 8 \ddagger$ & $146 \pm 66^{*}$ \\
\hline & G5 & $626 \pm 142$ & $110 \pm 9 *$ & $4.4 \pm 1.9^{*}$ & $311 \pm 56 \dagger$ & $33 \pm 4 \ddagger$ & $284 \pm 125^{*}$ \\
\hline & Evita XL & $786 \pm 224 *$ & $86 \pm 10^{*}$ & $3.2 \pm 1.0^{*}$ & $171 \pm 44$ & $32 \pm 11 \ddagger$ & $168 \pm 79^{*}$ \\
\hline \multirow[t]{6}{*}{ Pressure Assist/Control } & 840 & $806 \pm 222 \S$ & $76 \pm 14$ & $1.9 \pm 1.1$ & $189 \pm 35$ & $27 \pm 6 \ddagger$ & $96 \pm 70^{*}$ \\
\hline & Servo-i & $783 \pm 209 \S$ & $80 \pm 12 *$ & $2.5 \pm 1.0^{*}$ & $220 \pm 54 \dagger$ & $21 \pm 6$ & $107 \pm 55^{*}$ \\
\hline & e500 & $795 \pm 231 \S$ & $71 \pm 8$ & $1.7 \pm 0.5$ & $227 \pm 49 \dagger$ & $30 \pm 13 \neq$ & $78 \pm 47$ \\
\hline & Carestation & $777 \pm 222 \S$ & $77 \pm 7$ & $2.4 \pm 0.9 *$ & $195 \pm 32$ & $28 \pm 9 \ddagger$ & $109 \pm 54^{*}$ \\
\hline & G5 & $613 \pm 129$ & $112 \pm 7 *$ & $4.7 \pm 1.9^{*}$ & $303 \pm 20 \dagger$ & $37 \pm 5 \ddagger$ & $302 \pm 127^{*}$ \\
\hline & Evita XL & $801 \pm 226 \S$ & $86 \pm 10^{*}$ & $3.2 \pm 1.1^{*}$ & $180 \pm 45$ & $31 \pm 11 \ddagger$ & $165 \pm 85^{*}$ \\
\hline \multirow[t]{6}{*}{ Volume Assist/Control } & 840 & $416 \pm 25$ & $60 \pm 7$ & $1.2 \pm 0.4$ & ND & $165 \pm 163$ & $140 \pm 494 \|$ \\
\hline & Servo-i & $491 \pm 6 \dagger$ & $80 \pm 16 \mathbb{I}$ & $2.5 \pm 1.1 \Phi$ & ND & $150 \pm 97$ & $187 \pm 327 \|$ \\
\hline & e500 & $450 \pm 8$ & $83 \pm 33$ II & $2.1 \pm 1.5 \rrbracket$ & ND & $175 \pm 125$ & $269 \pm 527 \|$ \\
\hline & Carestation & $479 \pm 3 \dagger$ & $78 \pm 10 \mathrm{II}$ & $2.6 \pm 1.1 \Phi$ & ND & $158 \pm 135$ & $122 \pm 266$ \\
\hline & G5 & $434 \pm 5$ & $80 \pm 79$ & $2.5 \pm 0.9 \mathrm{II}$ & ND & $175 \pm 133 \ddagger$ & $216 \pm 505 \|$ \\
\hline & Evita XL & $414 \pm 4$ & $93 \pm 79$ & $3.6 \pm 1.4 \mathbb{I}$ & ND & $190 \pm 125$ & $486 \pm 543 \|$ \\
\hline \multicolumn{8}{|c|}{ 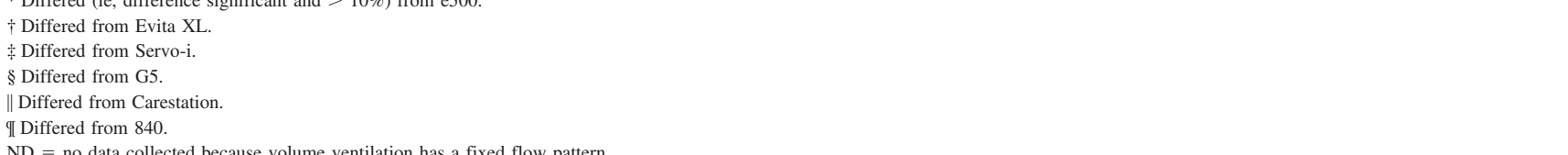 } \\
\hline
\end{tabular}

pressure-to-trigger decreased with the optimal configuration with the Servo-i and Evita XL. T90 decreased with the optimal configuration with the PB840, G5, and Evita XL. With all the ventilators except the Carestation and G5, the time-to-baseline-pressure and PTP decreased with the optimal configuration.

Figure 4 shows the PA/C results. Optimal versus default ventilator settings had no impact on $\mathrm{V}_{\mathrm{T}}$. With the PB840 and Evita XL, the optimal settings decreased the time-totrigger. With the Servo-i and Evita XL, the optimal settings decreased the pressure-to-trigger. With all the ventilators except Carestation and G5, T90, time-to-baselinepressure, and PTP decreased notably with the optimal configuration.

Figure 5 shows the VA/C results. There were important differences in ventilator triggering and initial gas delivery, but $\mathrm{V}_{\mathrm{T}}$ remained unchanged with all the ventilators. The e500 increased time-to-trigger and pressure-to-trigger with the square waveform. Time-to-baseline-pressure remained unchanged. With the PB840, e500, and G5, PTP increased with the square waveform.

\section{Effects of Muscle Effort}

In PS, variations in $\mathrm{P}_{\text {mus }}$ caused important differences (Fig. 6). All the ventilators except the e500 had increased
$\mathrm{V}_{\mathrm{T}}$ at the higher $\mathrm{P}_{\text {mus }}$. The e500 was the only ventilator to decrease time-to-trigger with increased $\mathrm{P}_{\text {mus }}$. Furthermore, all the ventilators showed sharp increases in pressure-totrigger with the higher $\mathrm{P}_{\text {mus }}$. Only the e500 had a decreased T90 as $\mathrm{P}_{\text {mus }}$ increased. However, all the ventilators exhibited a notable increase in both time-to-baseline-pressure and PTP at high $\mathrm{P}_{\text {mus }}$. The Servo-i was the only exception: time-to-baseline-pressure was unchanged.

Figure 7 shows important differences in response to $\mathrm{P}_{\text {mus }}$ during PA/C. $\mathrm{V}_{\mathrm{T}}$ increased with increased $\mathrm{P}_{\text {mus }}$ with all the ventilators. The PB840 had increased time-to-trigger with the higher $\mathrm{P}_{\text {mus }}$, and the Servo-i had decreased time-to-trigger with the higher $\mathrm{P}_{\text {mus }}$. All the other ventilators were unaffected. All the ventilators exhibited increased pressure-to-trigger with the higher $\mathrm{P}_{\text {mus }}$. The Servo-i, e500, and Evita XL had increased T90 at the higher $\mathrm{P}_{\text {mus. }}$. All except the Servo-i and Evita XL had increased time-to-baseline-pressure and PTP with the higher $\mathrm{P}_{\text {mus }}$.

Figure 8 shows important differences as $\mathrm{P}_{\text {mus }}$ was altered during VA/C. $\mathrm{V}_{\mathrm{T}}$ was unchanged by $\mathrm{P}_{\text {mus }}$. Time-totrigger decreased as $\mathrm{P}_{\text {mus }}$ decreased with the e500 and Evita XL; however, time-to-trigger increased in the PB840. All the ventilators had increased pressure-to-trigger as $P_{\text {mus }}$ increased. Both time-to-baseline-pressure and PTP increased markedly with all the ventilators at the higher $\mathrm{P}_{\text {mus }}$. 

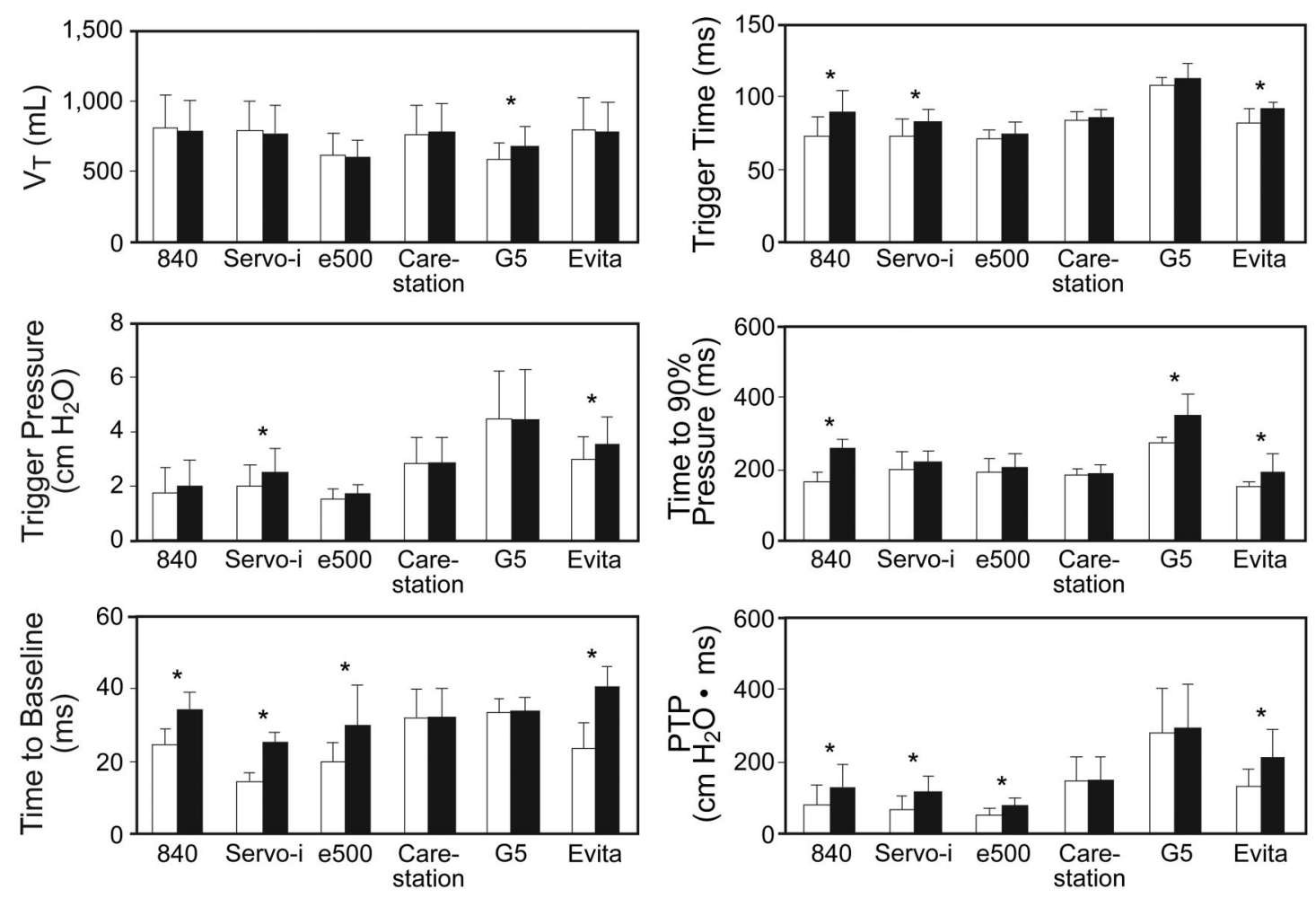

Fig. 3. Impact of "optimal" (white bars) versus manufacturer's default (black bars) ventilation settings during pressure support ventilation.

* "Important" difference $(P<.05$ and difference $>10 \%)$. The error bars represent one standard deviation. $V_{\mathrm{T}}=$ tidal volume. PTP $=$ pressure-time product.

\section{Effects of PEEP}

In all the ventilation modes, PEEP had no notable influence on any performance variable with any ventilator (data not shown).

\section{Effects of Lung Mechanics}

During PS, alterations in lung mechanics resulted in important differences (Fig. 9). With all the ventilators, the lower resistance increased the $\mathrm{V}_{\mathrm{T}}$, whereas the lower compliance and the higher resistance decreased the $\mathrm{V}_{\mathrm{T}}$. All the ventilators except the G5 exhibited increased time-to-trigger as resistance increased from C60/R5 to C60/R10. With all the ventilators, the pressure-to-trigger decreased as compliance decreased and resistance increased. Similarly, with all the ventilators except the PB840, T90 was shorter at C30/R10 than at C60/R5. Additionally, T90 was shorter with the Servo-i and Carestation at C60/R10 than at C60/ R5. With the Carestation and G5, the time-to-baselinepressure decreased as resistance increased and compliance decreased, and with the PB840 the time-to-baseline-pressure decreased as resistance decreased. With all the ventilators except the Evita XL, PTP was smaller at C30/R10 than at C60/R5. Furthermore, the Servo-i and PB840 had a greater PTP at C60/R10 than at C60/R5.
Figure 10 shows the impact of lung mechanics during PA/C. $\mathrm{V}_{\mathrm{T}}$ increased at C60/R5 versus C60/R10, and decreased at $\mathrm{C} 30 / \mathrm{R} 10$ versus $\mathrm{C} 60 / \mathrm{R} 5$ with all the ventilators. The PB840, Servo-i, Carestation, and Evita XL increased time-to-trigger at $\mathrm{C} 60 / \mathrm{R} 10$ versus $\mathrm{C} 60 / \mathrm{R} 5$. With all the ventilators, pressure-to-trigger decreased at $\mathrm{C} 60 / \mathrm{R} 5$ versus C30/R10. With the G5 and e500, pressure-to-trigger increased at C60/R5 versus C60/R10, whereas the Servo-i displayed the opposite result. All the ventilators except the PB840 and G5 had greater T90 at C60/R5 than at C60/ $\mathrm{R} 10$, and at C60/R5 than at C30/R10. Increased time-tobaseline-pressure was observed at $\mathrm{C} 60 / \mathrm{R} 5$ versus $\mathrm{C} 30 /$ R10 with the e500, Carestation, and G5. The PB840 had increased time-to-baseline-pressure at C60/R10 versus C60/R5, whereas the G5 had the opposite behavior. All the ventilators displayed increased PTP at C60/R10 versus C30/R10. The Servo-i had increased PTP at C60/R10 versus C60/R5, whereas the e500 had the opposite behavior.

Figure 11 shows the important differences as a result of lung-mechanics changes during VA/C. $\mathrm{V}_{\mathrm{T}}$ remained unchanged. The PB840 and G5 showed increased time-totrigger at C60/R10. The e500 exhibited increased time-totrigger at C60/R5. Similarly, all the ventilators except the Servo-i showed a decreased pressure-to-trigger at C30/ R10 versus C60/R5. Additionally, the e500 and Caresta- 

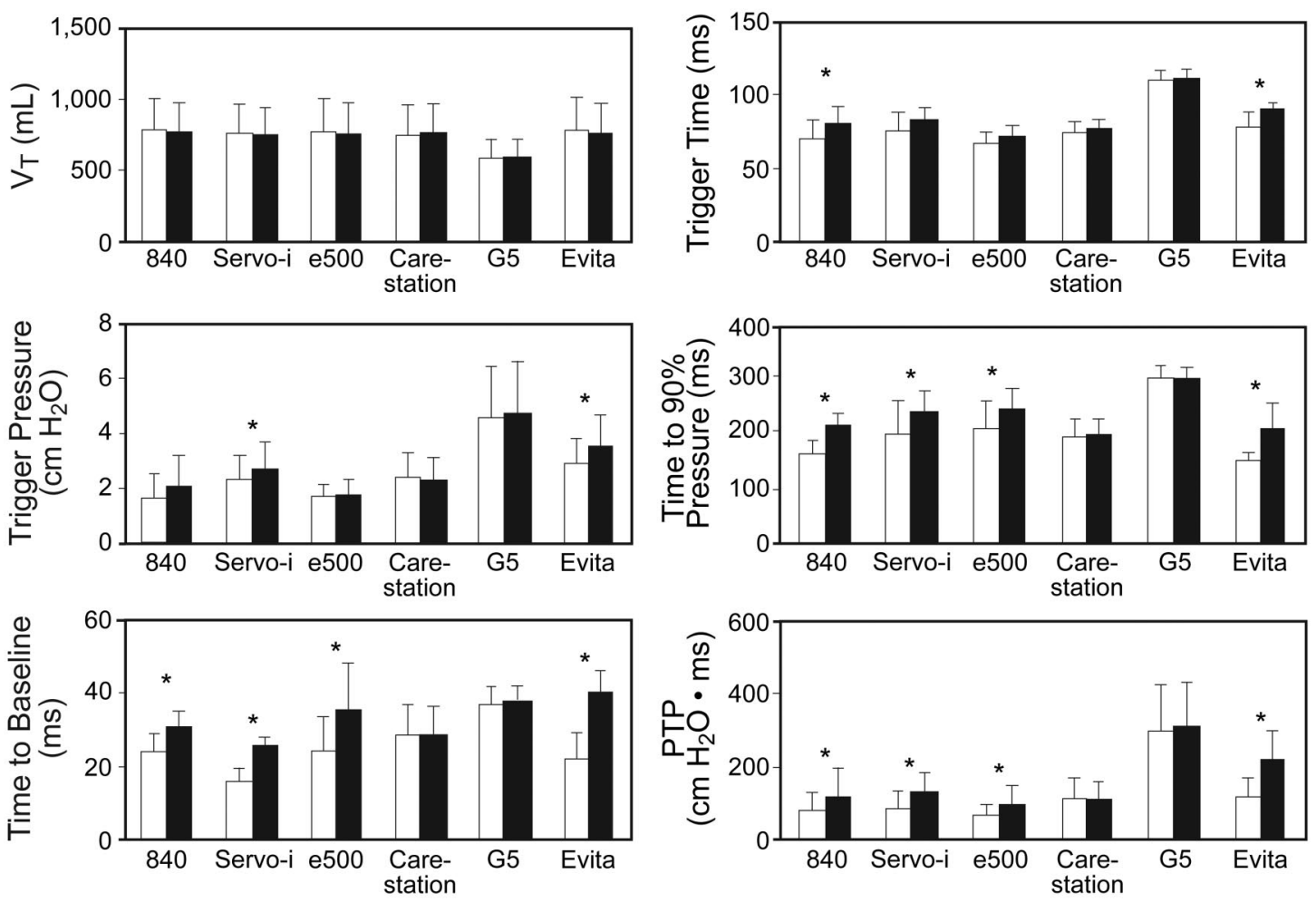

Fig. 4. Impact of "optimal" (white bars) versus manufacturer's default (black bars) ventilation settings during pressure assist/control ventilation. * "Important" difference $(P<.05$ and difference $>10 \%)$. The error bars represent one standard deviation. $V_{\mathrm{T}}=$ tidal volume. PTP $=$ pressure-time product.
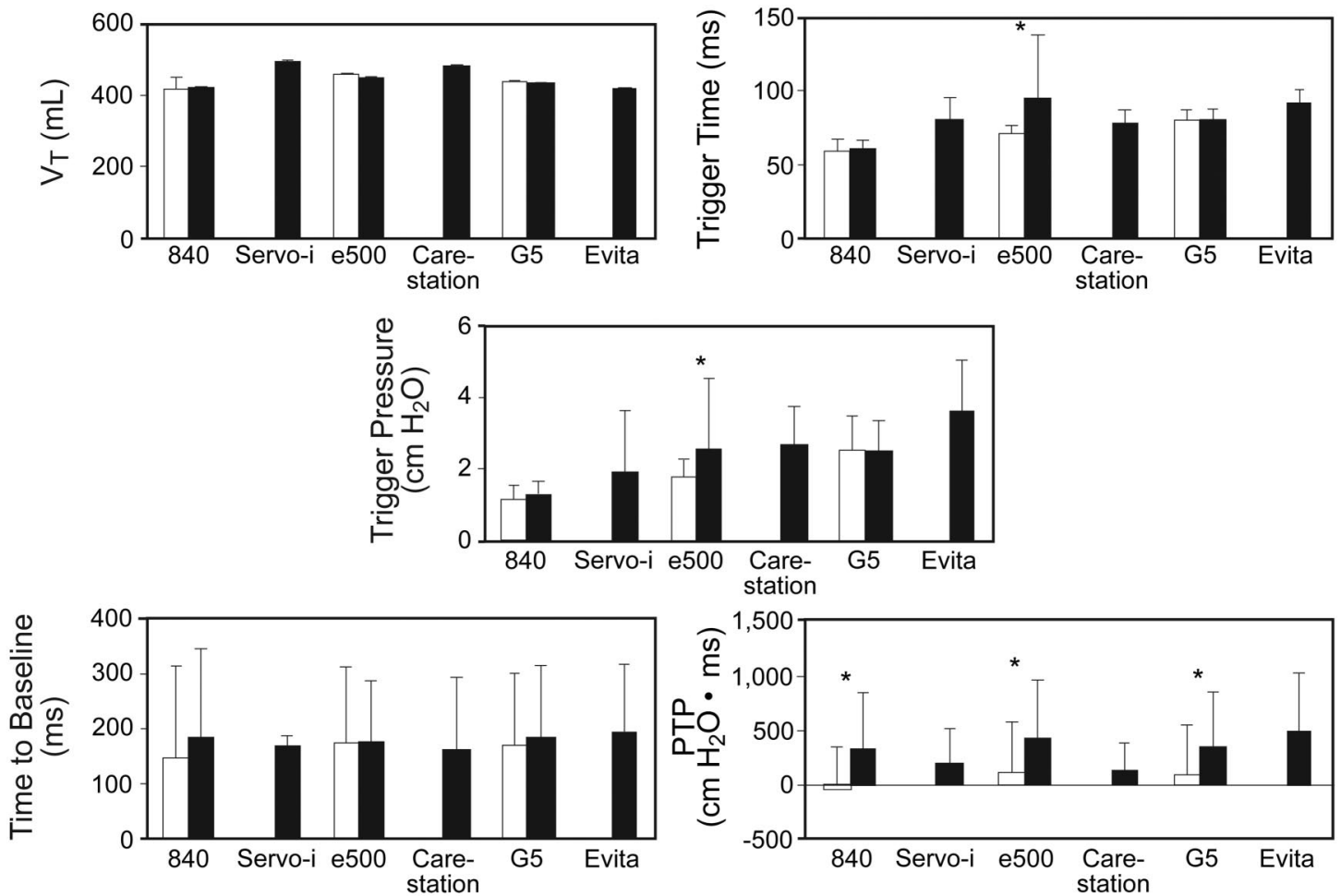

Fig. 5. Impact of "optimal" (white bars) versus manufacturer's default (black bars) ventilation settings during volume assist/control ventilation. * "Important" difference $(P<.05$ and difference $>10 \%)$. The error bars represent one standard deviation. $V_{\mathrm{T}}=$ tidal volume. PTP $=$ pressure-time product. 

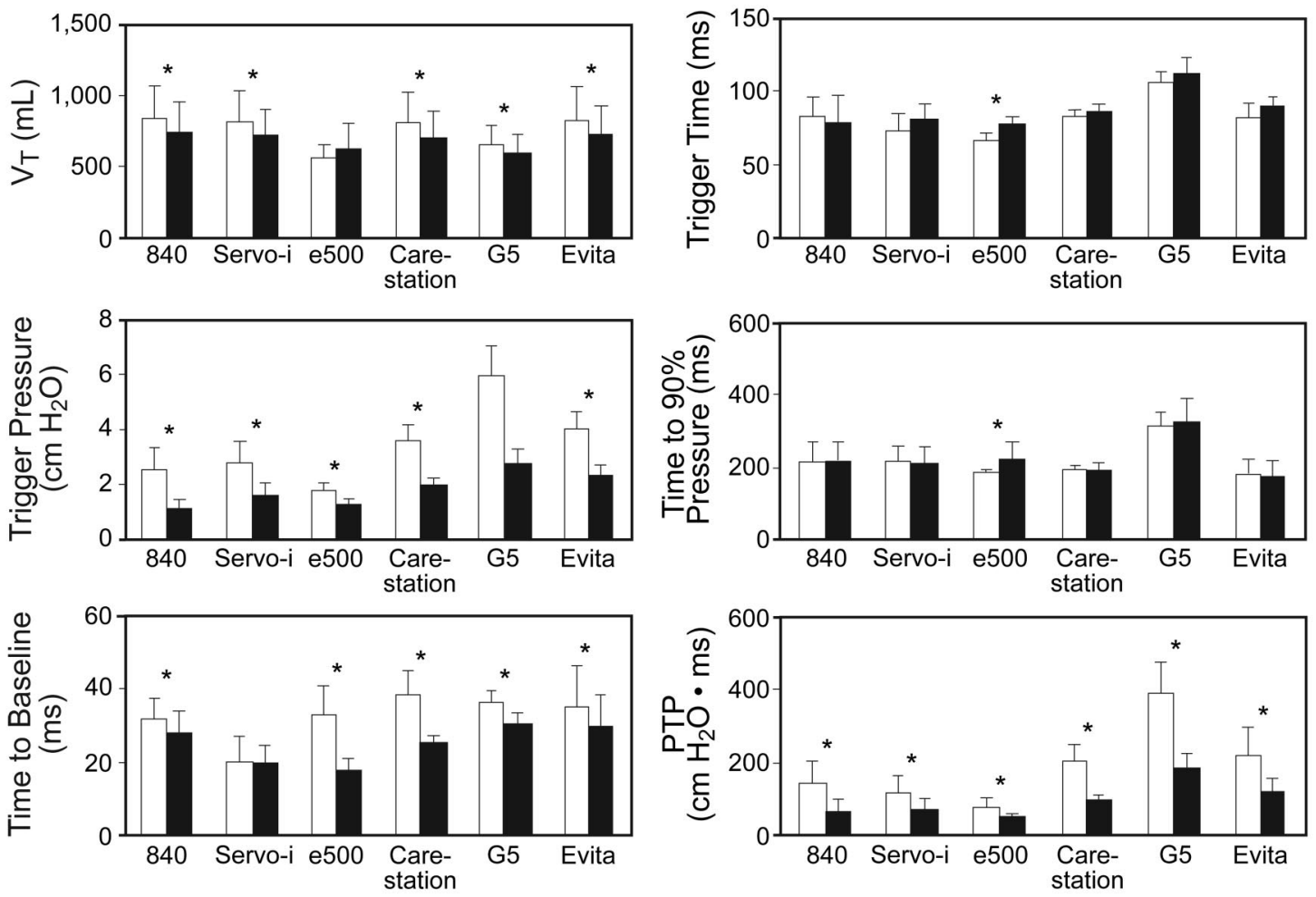

Fig. 6. Impact of simulated muscle effort of $10 \mathrm{~cm} \mathrm{H} \mathrm{H}_{2} \mathrm{O}$ (white bars) versus $5 \mathrm{~cm} \mathrm{H}_{2} \mathrm{O}$ (black bars) during pressure support ventilation. * "Important" difference $(P<.05$ and difference $>10 \%)$. The error bars represent one standard deviation. $V_{\mathrm{T}}=$ tidal volume. PTP $=$ pressure-time product.
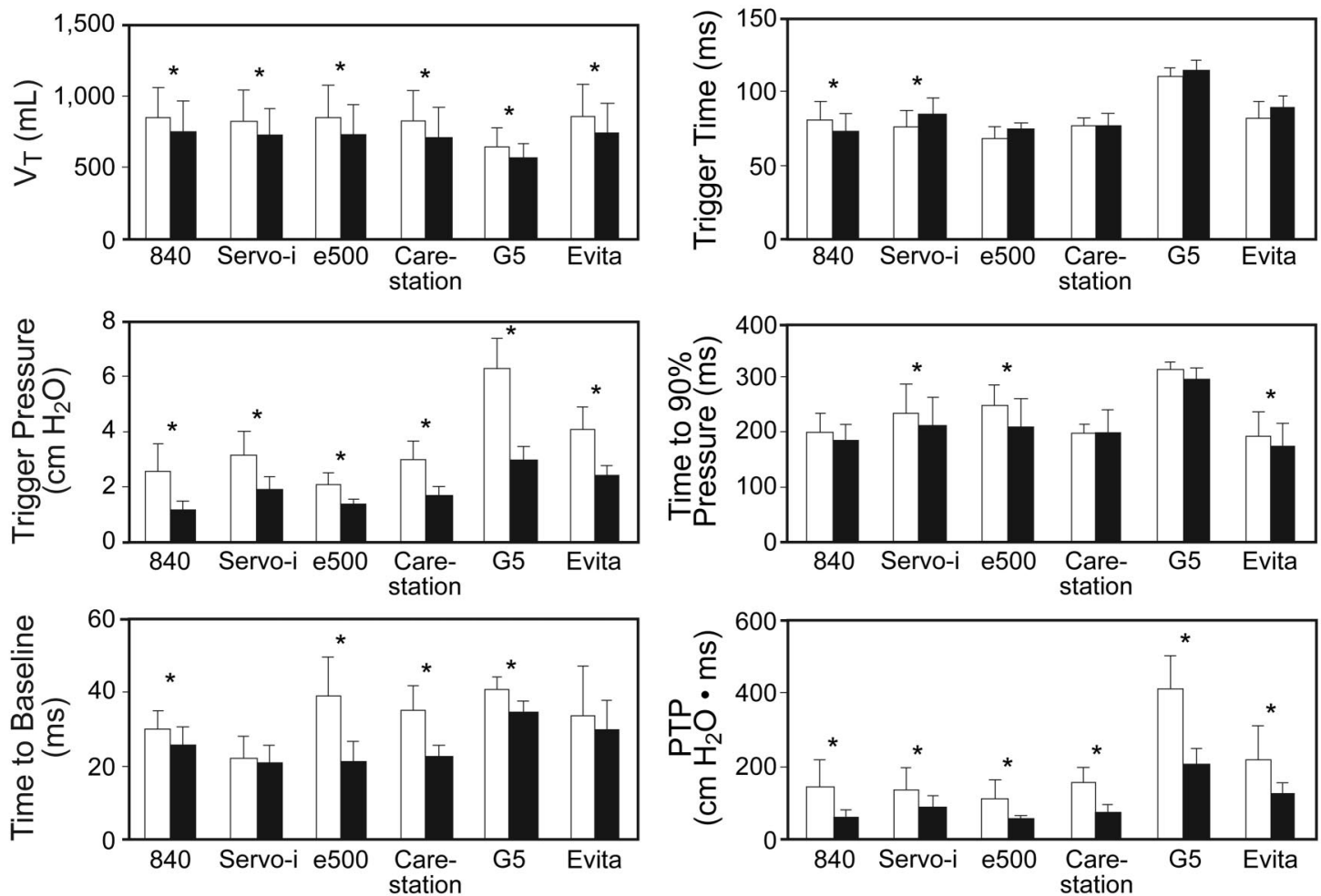

Fig. 7. Impact of simulated muscle effort of $10 \mathrm{~cm} \mathrm{H}_{2} \mathrm{O}$ (white bars) versus $5 \mathrm{~cm} \mathrm{H}_{2} \mathrm{O}$ (black bars) during pressure assist/control ventilation. * "Important" difference $(P<.05$ and difference $>10 \%)$. The error bars represent one standard deviation. $V_{\mathrm{T}}=$ tidal volume. PTP $=$ pressure-time product. 

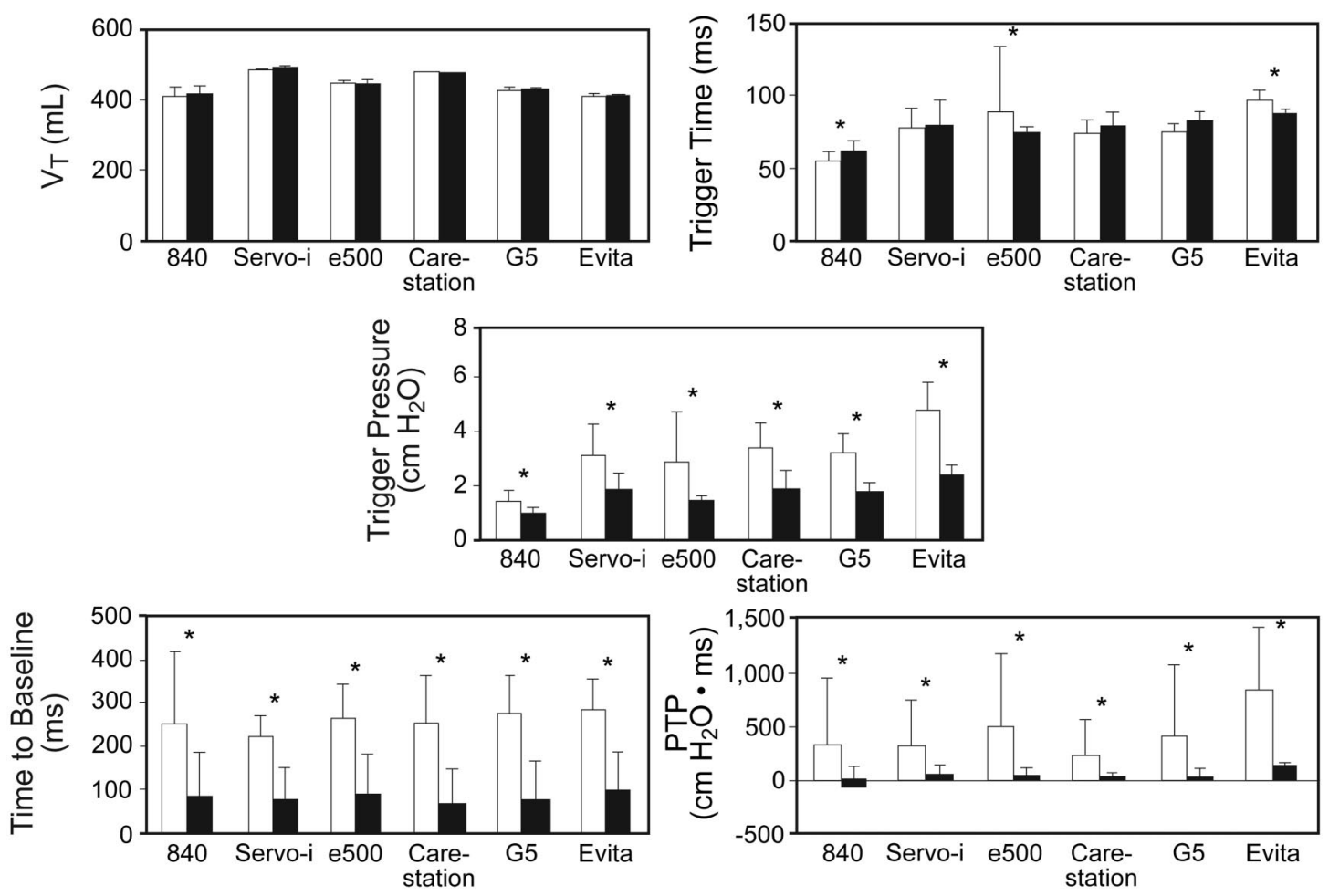

Fig. 8. Impact of simulated muscle effort of $10 \mathrm{~cm} \mathrm{H}_{2} \mathrm{O}$ (white bars) versus $5 \mathrm{~cm} \mathrm{H}_{2} \mathrm{O}$ (black bars) during volume assist/control ventilation. * "Important" difference $(P<.05$ and difference $>10 \%)$. The error bars represent one standard deviation. $\mathrm{V}_{\mathrm{T}}=$ tidal volume. PTP $=$ pressure-time product.

tion had decreased pressure-to-trigger at C60/R10 versus C60/R5. Time-to-baseline-pressure and PTP increased with all the ventilators at C60/R5.

\section{Discussion}

Our primary findings are:

- There were important performance differences among the 6 ventilators, and the differences were greatest during $\mathrm{VA} / \mathrm{C}$.

- The most inconsistent mode across all evaluations and ventilators was VA/C. With some of the ventilators in some of the test scenarios the standard deviations for time-to-baseline-pressure and PTP exceeded the mean value.

- In general, the optimal settings established by us-or the ventilator in the case of the e500-performed better than the manufacturers' default settings, across all the ventilators.

- $\mathrm{P}_{\text {mus }}$ profoundly affected most of the variables in all the ventilation modes. The greatest effect during all 3 modes was on pressure-to-trigger, time-to-baseline-pressure, and PTP. During PS and PA/C, $\mathrm{V}_{\mathrm{T}}$ was also affected.

- Altering the lung mechanics markedly affected all the variables during PS and PA/C. During VA/C the same was true except for $\mathrm{V}_{\mathrm{T}}$.

- PEEP had no significant effect on any variable, in any mode, with any ventilator.

\section{Differences Between the Ventilators}

The clinical importance of the performance differences between the ventilators is difficult to evaluate. There are no standards for time-to-trigger, pressure-to-trigger, PTP, or T90. However, most would agree that the ventilator should respond rapidly to the patient's inspiratory effort. ${ }^{10,12}$ Ideally, this response should be instantaneous. ${ }^{13}$ Practically, it seems reasonable for the ventilator to respond in $<90 \mathrm{~ms},{ }^{10,11}$ that the required pressure-to-trigger is less than or equal to the normal intrathoracic pressure change during quiet breathing or $<3 \mathrm{~cm} \mathrm{H}_{2} \mathrm{O}$, and that the post-trigger pressure should return to baseline in $<30 \mathrm{~ms}$. Considering these 3 variables, the trigger PTP should be $<200 \mathrm{~cm} \mathrm{H}_{2} \mathrm{O} \cdot \mathrm{ms}$. The only ventilator that did not meet that PTP target was the G5, which had a high pressureto-trigger and long time-to-trigger and time-to-baselinepressure in all modes tested. Attention to the initial gasdelivery capabilities of the G5 by the manufacturer is indicated. The ideal target T90 during pressure ventilation 

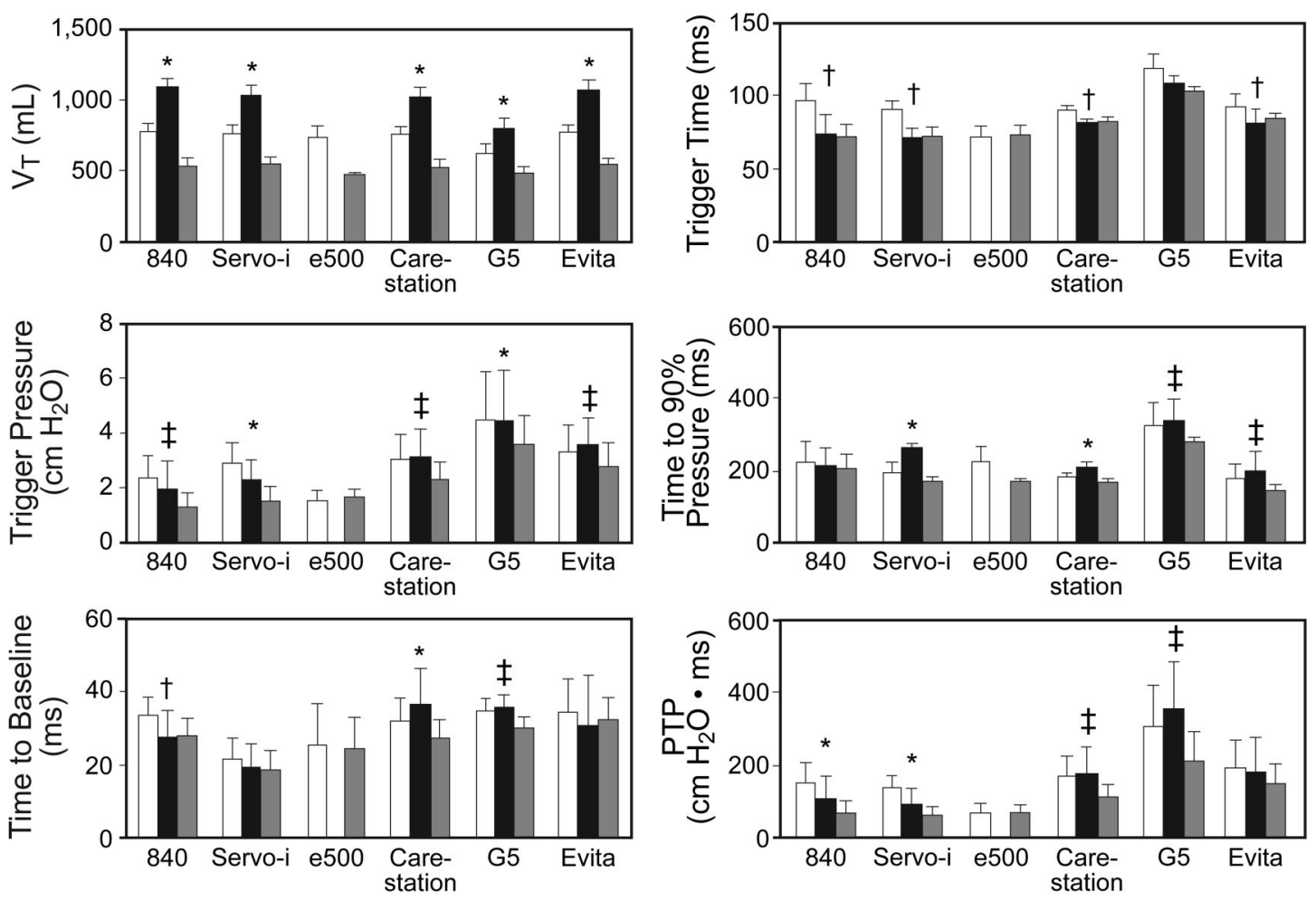

Fig. 9. Impact of 3 combinations of compliance and resistance during pressure support ventilation. White bars (C60/R10) $=$ compliance $60 \mathrm{~mL} / \mathrm{cm} \mathrm{H}_{2} \mathrm{O}$ and resistance $10 \mathrm{~cm} \mathrm{H}_{2} \mathrm{O} / \mathrm{L} / \mathrm{s}$. Black bars (C60/R5) = compliance $60 \mathrm{~mL} / \mathrm{cm} \mathrm{H}_{2} \mathrm{O}$ and resistance $5 \mathrm{~cm} \mathrm{H} \mathrm{H}_{2} \mathrm{O} / \mathrm{L} / \mathrm{s}$. Grey bars $(\mathrm{C} 30 / \mathrm{R} 10)=$ compliance $30 \mathrm{~mL} / \mathrm{cm} \mathrm{H}_{2} \mathrm{O}$ and resistance $10 \mathrm{~cm} \mathrm{H} \mathrm{H}_{2} \mathrm{O} / \mathrm{L} / \mathrm{s}$. * "Important" difference $(P<.05$ and difference $>10 \%)$ between both C60/R10 and C60/R5 and between C60/R5 and C30/R10. † "Important" difference between C60/R10 and C60/R5. $\ddagger$ "Important" difference between C60/R5 and C30/R10. The error bars represent one standard deviation. $\mathrm{V}_{\mathrm{T}}=$ tidal volume. PTP $=$ pressuretime product.

is harder to predict, but if we accept that critically ill patients generally have an inspiratory time $<1.0 \mathrm{~s}$ and desire rapid gas delivery early in inspiration, ${ }^{1}$ a $\mathrm{T} 90$ of $<200 \mathrm{~ms}$ seems a reasonable target.

\section{Volume Assist/Control}

The greatest differences between the ventilators and within each ventilator was during VA/C. As noted in Table 1, the standard deviations of most of the variables were much greater during VA/C than during PS or PA/C. This is a result of the fixed flow that was set on each ventilator to achieve an inspiratory time of 0.8 second with a $\mathrm{V}_{\mathrm{T}}$ of $500 \mathrm{~mL}$. With square waveform this resulted in a peak flow of $37.5 \mathrm{~L} / \mathrm{min}$, and with decelerating flow a peak flow of $60-70 \mathrm{~L} / \mathrm{min}$, depending on the ventilator's algorithm. Essentially, these settings were unable to always meet the inspiratory demand of the lung model (see Fig. 2), which ranged from $21 \mathrm{~L} / \mathrm{min}$ to $41 \mathrm{~L} / \mathrm{min}$ at a $\mathrm{P}_{\text {mus }}$ of $5 \mathrm{~cm} \mathrm{H}_{2} \mathrm{O}$, and $43 \mathrm{~L} / \mathrm{min}$ to $81 \mathrm{~L} / \mathrm{min}$ at a $\mathrm{P}_{\text {mus }}$ of $10 \mathrm{~cm} \mathrm{H}_{2} \mathrm{O}$.

As noted in Figure 5, little difference existed between square and decelerating flow in the ventilators that have this option (PB840, e500, and G5), except for PTP. This appears to be a result of small insignificant differences in pressure-to-trigger and time-to-trigger. With the PB840, e500, and G5, time-to-trigger and pressure-to-trigger were slightly shorter/smaller during decelerating waveform (see Fig. 5). Note that the Servo-i does not offer typical volume ventilation. ${ }^{14}$ In the VA/C mode, demand flow is always available if peak inspiratory flow exceeds the set level, but in our evaluation this did not improve the functioning of the Servo-i during VA/C. Our VA/C results further highlight concerns regarding patient-ventilator synchrony during volume-targeted ventilation.

\section{Pressure Support and Pressure Assist/Control}

As has been shown previously, essentially no differences exist between PS and PA/C in patients actively triggering the ventilator, except for the mechanism that terminates the breath. ${ }^{2}$ In PS the breath terminates at a percentage of the patient's peak inspiratory flow, whereas in PA/C the breath is terminated at a set inspiratory time. ${ }^{2}$ Our analysis supports this: for the individual ventilators there were no important differences in any variable we evaluated between PS and PA/C. Essentially, PS and PA/C 

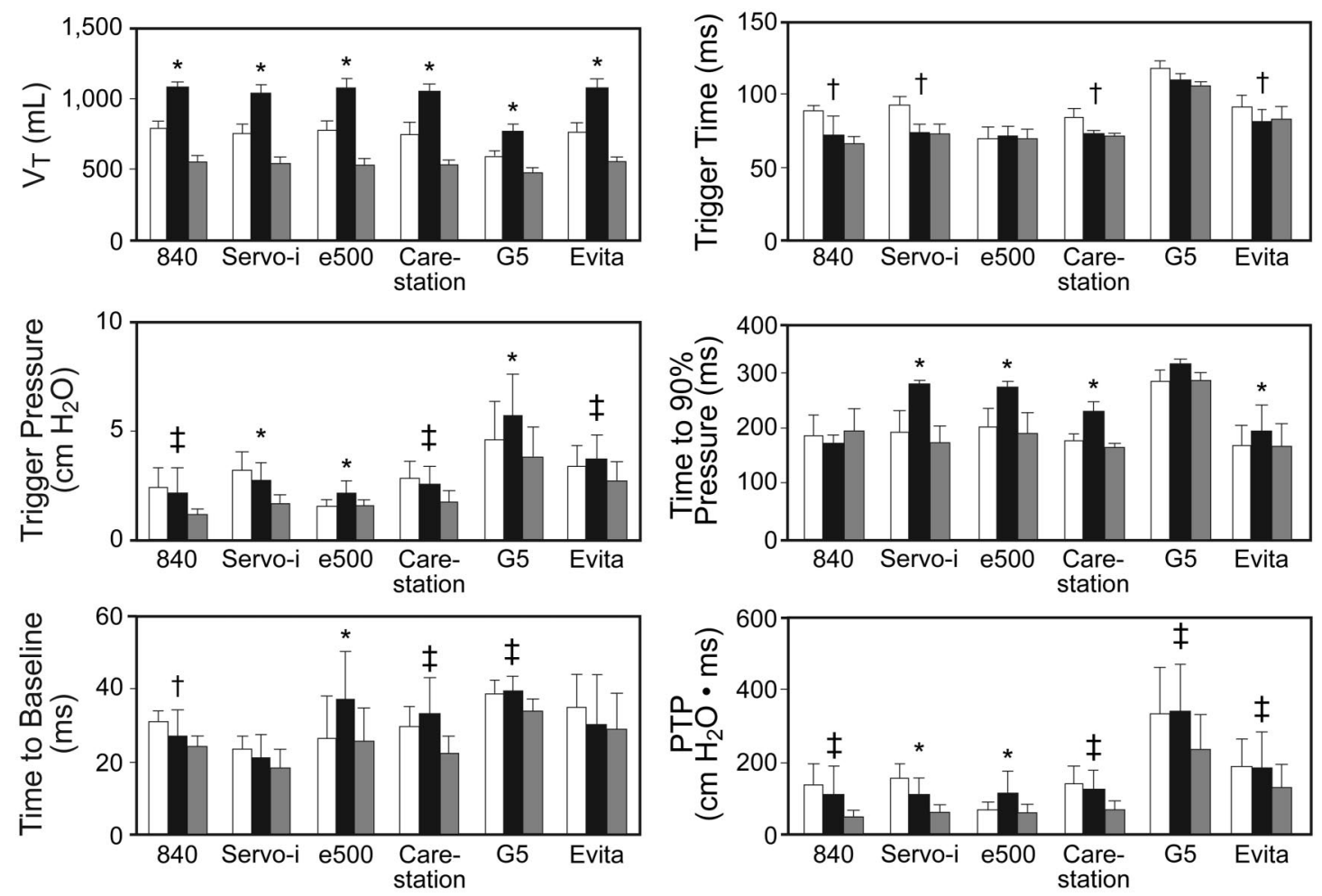

Fig. 10. Impact of 3 combinations of compliance and resistance during pressure assist/control ventilation. White bars $(\mathrm{C} 60 / \mathrm{R} 10)=$ compliance $60 \mathrm{~mL} / \mathrm{cm} \mathrm{H}_{2} \mathrm{O}$ and resistance $10 \mathrm{~cm} \mathrm{H}_{2} \mathrm{O} / \mathrm{L} / \mathrm{s}$. Black bars (C60/R5) = compliance $60 \mathrm{~mL} / \mathrm{cm} \mathrm{H}_{2} \mathrm{O}$ and resistance $5 \mathrm{~cm} \mathrm{H} \mathrm{H}_{2} \mathrm{O} / \mathrm{L} / \mathrm{s}$. Grey bars $(\mathrm{C} 30 / \mathrm{R} 10)=$ compliance $30 \mathrm{~mL} / \mathrm{cm} \mathrm{H}_{2} \mathrm{O}$ and resistance $10 \mathrm{~cm} \mathrm{H}$ O/L/s. * "Important" difference $(P<.05$ and difference $>10 \%)$ between both C60/R10 and C60/R5 and between C60/R5 and C30/R10. † "Important" difference between C60/R10 and C60/R5. $\ddagger$ "Important" difference between C60/R5 and C30/R10. The error bars represent one standard deviation. $\mathrm{V}_{\mathrm{T}}=$ tidal volume. PTP $=$ pressuretime product.

could be used interchangeably, assuming the termination criteria or inspiratory time is set to equal the patient's neurologic inspiratory time. ${ }^{2}$

As shown in Figures 3 and 4, there were important differences for individual ventilators between the default and optimal settings in both PS and PA/C. The only ventilator in which the default and optimal settings resulted in exactly the same response in both PS and PA/C was the Carestation, because the optimal and default settings were essentially the same (see Table 2). With the G5 there were no important differences during PA/C, except in $\mathrm{V}_{\mathrm{T}}$ and T90, favoring optimal settings. Across all the ventilators, where differences did occur, the differences favored the optimal settings. It seems reasonable to expect that today's ventilators should be able to adjust their default settings to the individual demands of the patient. If the user can make these adjustments based on visual assessment of the patient's airway pressure waveform, the ventilator should be able to make the same adjustments based on its assessment of that waveform. We would expect future generations of mechanical ventilators to automatically make these adjustments. Of the ventilators we tested, the only one that automatically determined the optimal settings was the e500. ${ }^{15}$

\section{Effect of Muscle Effort}

Increasing $\mathrm{P}_{\text {mus }}$ had the greatest effect during $\mathrm{VA} / \mathrm{C}$, because VA/C cannot increase peak flow as patient demand increases. However, we did not expect the Servo-i to respond as it did, since in VA/C the Servo-i adds demand flow to the set flow if demand increases. ${ }^{14}$ As seen in Figure 8, increasing the $\mathrm{P}_{\text {mus }}$ to $10 \mathrm{~cm} \mathrm{H}_{2} \mathrm{O}$ in VA/C markedly affected the pressure-to-trigger, time-to-baselinepressure, and PTP with all the ventilators. PS and PA/C responded essentially the same when $\mathrm{P}_{\text {mus }}$ was increased: Figures 6 and 7 are essentially identical. As with VA/C, the primary factors affected by higher $\mathrm{P}_{\mathrm{mus}}$ were pressureto-trigger, time-to-trigger, and PTP, but with PS and PA/C both time-to-baseline-pressure and $\mathrm{V}_{\mathrm{T}}$ increased with most of the ventilators. However, the increases were not as marked as in VA/C. All of these responses were expected: with increasing demand the time-to-trigger is expected to be reached sooner, but pressure-to-trigger and PTP are expected to be greater because of the more rapid decrease in system pressure. Thus, all of these ventilators in PS or $\mathrm{PA} / \mathrm{C}$ are better capable of appropriately responding to increased patient demand than they are in VA/C. 

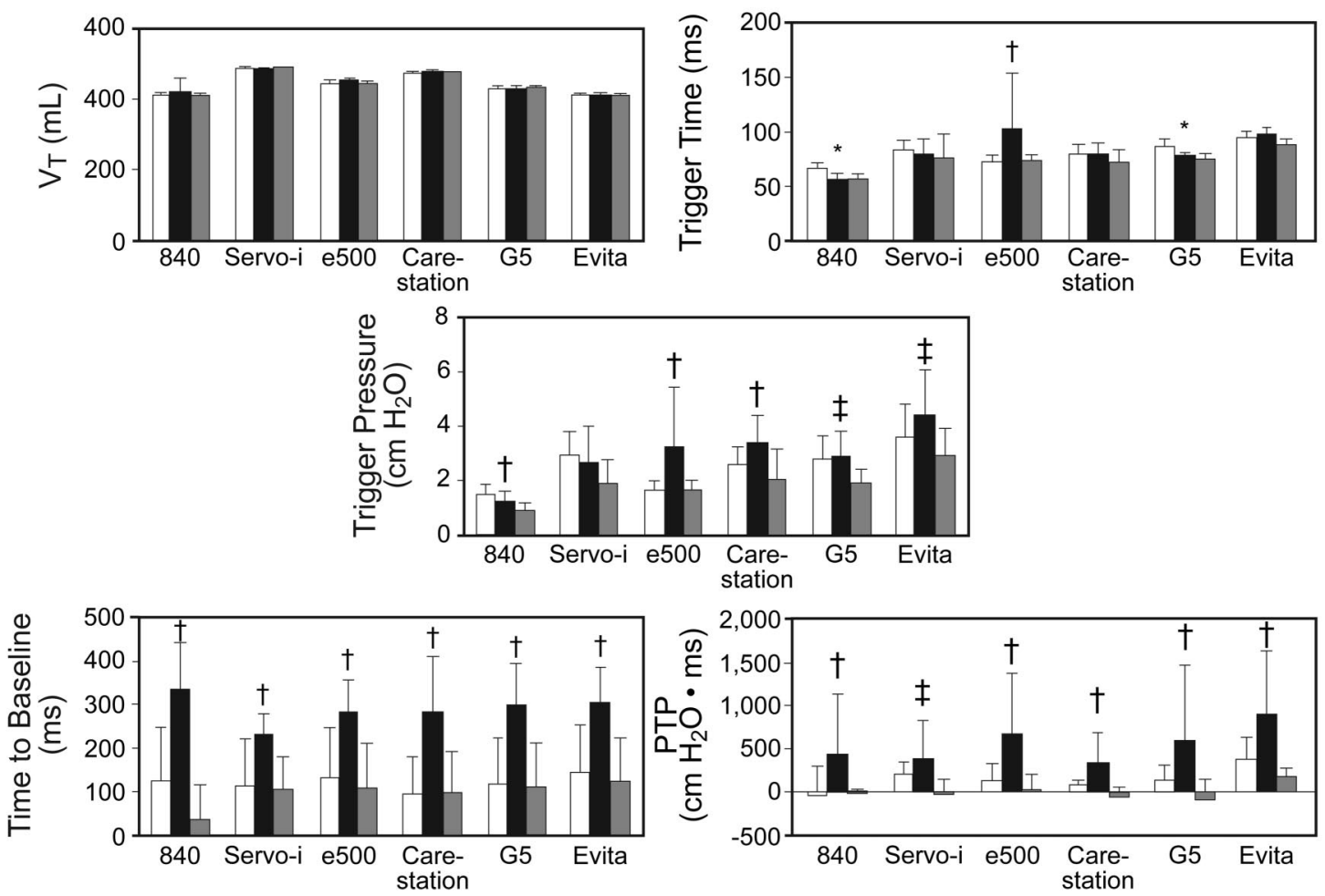

Fig. 11. Impact of 3 combinations of compliance and resistance during volume assist/control ventilation. White bars (C60/R10) $=$ compliance $60 \mathrm{~mL} / \mathrm{cm} \mathrm{H}_{2} \mathrm{O}$ and resistance $10 \mathrm{~cm} \mathrm{H}_{2} \mathrm{O} / \mathrm{L} / \mathrm{s}$. Black bars $(\mathrm{C} 60 / \mathrm{R} 5)=$ compliance $60 \mathrm{~mL} / \mathrm{cm} \mathrm{H}_{2} \mathrm{O}$ and resistance $5 \mathrm{~cm} \mathrm{H} \mathrm{H}_{2} \mathrm{O} / \mathrm{L} / \mathrm{s}$. Grey bars $(\mathrm{C} 30 / \mathrm{R} 10)=$ compliance $30 \mathrm{~mL} / \mathrm{cm} \mathrm{H}_{2} \mathrm{O}$ and resistance $10 \mathrm{~cm} \mathrm{H} \mathrm{H}_{2} \mathrm{O} / \mathrm{L} / \mathrm{s}$. * "Important" difference $(P<.05$ and difference $>10 \%)$ between both C60/R10 and C60/R5. † "Important" difference between C60/R10 and C60/R5 and between C60/R5 and C30/R10. $\ddagger$ "Important" difference between C60/R5 and C30/R10. The error bars represent one standard deviation. $\mathrm{V}_{\mathrm{T}}=$ tidal volume. PTP $=$ pressuretime product.

\section{Effect of Compliance and Resistance}

As expected, in most of the PS and PA/C comparisons all the variables changed as lung mechanics were changed, but individual ventilators responded in the same manner in PS and PA/C (see Figs. 9 and 10). In general, decreasing the resistance increased the $\mathrm{V}_{\mathrm{T}}$ and the ventilator's response to patient demand. Decreasing the compliance had a similar effect on ventilator response, since a less compliant system can be decompressed more rapidly, but, as expected, as compliance decreased, $\mathrm{V}_{\mathrm{T}}$ also decreased. During VA/C a decrease in resistance delayed ventilator response, and a decrease in compliance increased response; however, with VA/C, $\mathrm{V}_{\mathrm{T}}$ was not affected by changes in lung mechanics (see Fig. 11).

\section{Comparison to Previous Studies}

Our data differ somewhat from those of other groups. ${ }^{2-9,12}$ A primary reason is the lung model we used. Others have primarily used the Michigan Instruments Training and Test Lung, which is a mechanical lung model in which time-to-trigger, pressure-to-trigger, and trigger PTP are based on changes in airway pressure in the ventilator circuit. ${ }^{2}$ As one might expect, there is a normal delay between the respiratory center signaling the diaphragm to inspire and actual changes in pressure and flow at the airway. ${ }^{13}$ The ASL 5000 lung model moves the evaluation of these variables one step closer to the respiratory center. The measurement of time-to-trigger, pressure-to-trigger, and trigger PTP is based on changes in the equivalent of the pleural pressure. Thus, the time-to-trigger is longer, and the pressure-to-trigger and PTP would be expected to be greater with the ASL 5000 than with the Michigan Instruments Training and Test Lung, regardless of the ventilator evaluated.

The impact of the lung model used is highly evident when our data are compared to those of Thille et al. ${ }^{12}$ They used the Michigan Instruments Training and Test Lung to compare the initial gas delivery of the e500, Carestation, Evita XL, PB840, and Servo-i to that of older-generation ventilators during PS. With all of the ventilators the timeto-trigger was about $30 \mathrm{~ms}$ faster than we found. However, time-to-trigger with the Carestation, Evita XL, PB840, and Servo-i in their neonatal configurations during $\mathrm{PA} / \mathrm{C}$ were essentially the same as in our study when they used the 
ASL 5000. ${ }^{11}$ Our data and those of Thille et al ${ }^{12}$ and Williams et $\mathrm{a}^{2}$ clearly indicate that this newest generation of ICU ventilator is generally more responsive and better capable of pressurization of a lung model than were previous-generation ventilators, but some of the newer ventilators still perform inadequately in some scenarios.

\section{Limitations}

The primary limitation of this study is that it was performed with a lung model rather than with patients. However, the use of a lung model ensures that each ventilator is compared under equal conditions. A lung model also keeps the compliance linear throughout inspiration, whereas in a patient, compliance changes as the $\mathrm{V}_{\mathrm{T}}$ changes. The criteria we used to set trigger sensitivity, rise time, and termination criteria that we considered optimal may not be the optimal approach used by other experts. However, our approach was consistent across all ventilators and established fixed criteria from which to compare ventilator performance. During VA/C we made no adjustments after setting the VA/C variables. However, the set $\mathrm{V}_{\mathrm{T}}(500 \mathrm{~mL})$ during all the evaluations was greater than the measured $\mathrm{V}_{\mathrm{T}}$ of the lung model (see Table 1). Increasing the ventilator peak flow in VA/C may have improved the ventilator's ability to match the lung model's demand, but to maintain a 500-mL $\mathrm{V}_{\mathrm{T}}$, inspiratory time would have had to have been shorter than the lung model's 0.8 second inspiratory time. In addition, not all possible test conditions were evaluated, so we cannot be assured that the tested ventilators will respond as observed in all clinical scenarios. Finally, we tested only one of each ventilator model, so we are not sure that all ventilators of a given model will respond the same way. However, the studied ventilators were either provided by the manufacturer specifically for this evaluation or had just received their preventive maintenance by our biomedical engineering staff.

\section{Conclusions}

There were important performance differences between the ventilators, and the differences were greatest during $\mathrm{VA} / \mathrm{C}$. In general, the settings we chose as "optimal" performed better than the manufacturers' default settings. Altering $\mathrm{P}_{\text {mus }}$ and the lung mechanics profoundly affected most of the evaluated variables during all the ventilation modes. PS and PA/C performed equivalently. VA/C should be used cautiously in patients with high ventilatory demand. Most of the ventilators performed at an acceptable level during the majority of evaluations, but some performed inadequately in some tests.

\section{REFERENCES}

1. Kacmarek RM, Hess DR. Mechanical ventilation for the surgical patient. In: Longnecker DE, Brown DL, Newman MF, Zapol WM, editors. Anesthesiology. New York: McGraw-Hill; 2008:1852-1872.

2. Williams P, Muelver M, Kratohvil J, Ritz R, Hess DR, Kacmarek RM. Pressure support and pressure assist/control: are there differences? An evaluation of the newest intensive care unit ventilators. Respir Care 2000;45(10):1169-1181.

3. Takeuchi M, Williams P, Hess D, Kacmarek RM. Continuous positive airway pressure in new-generation mechanical ventilators: a lung model study. Anesthesiology 2002;96(1):162-172.

4. Richard JC, Carlucci A, Brenton L, Langlais N, Jaber S, Maggiore S, et al. Bench testing of pressure support ventilation with three different generations of ventilators. Intensive Care Med 2002;28(8):10491057.

5. Tassaux D, Strasser S, Fonseca S, Dalmas E, Jolliet P. Comparative bench study of triggering, pressurization, and cycling between the home ventilator VPAP II and three ICU ventilators. Intensive Care Med 2002;28(9):1254-1261.

6. Tung A, Drum ML, Morgan S. Effect of inspiratory time on tidal volume delivery in anesthesia and intensive care unit ventilators operating in pressure control mode. J Clin Anesth 2005;17(1):8-15.

7. Jaber S, Tassaux D, Sebbane M, Pouzeratte Y, Battisti A, Capdevila $\mathrm{X}$, et al. Performance characteristics of five new anesthesia ventilators and four intensive care ventilators in pressure-support mode. Anesthesiology 2006;105(5):944-952.

8. Vignaux L, Tassaux D, Jolliet P. Performance of noninvasive ventilation modes on ICU ventilators during pressure support: a bench model study. Intensive Care Med 2007;33(8):1444-1451.

9. Jiao G-Y, Newhart JW. Bench study on active exhalation valve performance. Respir Care 2008;53(12):1697-1702.

10. Ferreira JC, Chipman DW, Hill NS, Kacmarek RM. Bilevel vs ICU ventilators providing noninvasive ventilation: effect of system leaks. A COPD lung model comparison. Chest 2009;136(2):448-456.

11. Marchese AD, Chipman D, de la Oliva P, Kacmarek RM. Adult ICU ventilators to provide neonatal ventilation: a lung simulator study. Intensive Care Med 2009;35(4):631-638.

12. Thille AW, Lyazidi A, Richard JC, Galia F, Brochard L. A bench study of intensive-care-unit ventilators: new versus old and turbinebased versus compressed gas-based ventilators. Intensive Care Med 2009;35(8):1368-1376.

13. Sinderby C, Navalesi P, Beck J, Skrobik Y, Comtois, N, Friberg S, et al. Neural control of mechanical ventilation in respiratory failure. Nat Med 1999;5(12):1433-1436.

14. Servo i V3-2, User's Manual, Maquet Critical Care AB SE-171. Solna, Sweden: Maquet

15. The Newport e500 Wave Ventilator Operating Manual. OPR500US Rev. Costa Mesa, CA: Newport Medical Instruments; December 2005.

This article is approved for Continuing Respiratory Care Education credit. For information and to obtain your CRCE

(free to AARC members) visit www.RCJournal.com

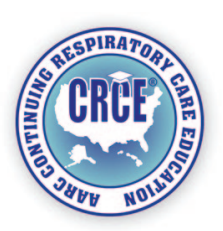

